\title{
Exploration and Practice of Innovative Teaching Methods Based on Theory of Machines and Mechanisms
}

\author{
Di Zhang \\ School of Mechanical and Electrical Engineering \\ Shanghai Jian Qiao University \\ Shanghai 201306, China \\ Email: dizhang@outlook.com
}

\author{
Lihua liu \\ School of Mechanical and Electrical Engineering \\ Shanghai Jian Qiao University \\ Shanghai 201306, China \\ Email: dizhang@outlook.com
}

\begin{abstract}
Theory of machines and mechanisms is one of the important technical foundation courses for mechanical students in universities. The goals of this paper are to stimulate the learning interest of students and develop students' innovative abilities. On this basis, this paper introduces the deficiencies of the curriculum existed in the traditional teaching. And it put forward five innovative teaching methods including teaching method, course design, experimental teaching, extracurricular activities of science technology and research projects in the course of theory of machines and mechanisms. In this way, the students' enthusiasm for learning and curiosity can be stimulated.
\end{abstract}

Keywords-Theory of machines and mechanisms, Curriculum design, Innovation ability, Teaching method

\section{INTRODUCTION}

Innovation is the soul of a nation and also the inner driving force for the development of science and technology in a country. Having innovation consciousness, innovative thinking and innovative ability will be the basic goals of talent cultivation in the era of knowledge economy. At present, the country is in great demand of the high-quality and comprehensive talents, especially those with strong innovative capabilities. Research and development of a large number of original products can fundamentally transform one country from a manufacturing country to an innovative country. Therefore, it is one of the important contents of the current teaching and research in colleges and universities to deeply study the methods in training of the innovation talents [1,2].

Theory of machines and mechanisms is an important professional and technical basic course of mechanical engineering, especially for the students majored in mechanical design, manufacturing and automation. Compared with the other courses, the course of the theory of machines and mechanisms has an irreplaceable important role in cultivating students' innovative ability. The mission of the major is to enable students to master the basic theories and skills of mechanics and mechanical system dynamics as well as the design analysis methods of common institutions. Meanwhile, mastering the ability to formulating a mechanical system movement program is also an important mission of the major. Through this course, students can not only lay a solid theoretical foundation for the following-up mechanical courses, but also will enhance the adaptability to mechanical work and improve the ability of innovation and development. In fact, the ability of innovation and development will enable students to reserve a lifetime of inexhaustible energy for academic innovation and technological reform [2]. It is widely known that many famous universities attach a great importance to the cultivation of students' innovative abilities. In the course system, they set up the relevant innovative design courses, practice sessions and innovation laboratories. They adopt a project-based teaching mode, which is characterized by: (1) emphasizing general education and boarding professional foundation. (2) Focusing on practical teaching. Generally, students must participate in scientific research or innovation activities to obtain scientific research credits, by which can truly train students' ability to work, innovation and even organizational skills. Compared with the developed countries in western countries, there is still a gap between the ability of innovation and design of higher education institutions in china. At present, the traditional teaching of theory of machines and mechanisms has the following deficiencies [3].

(1) Pay more attention to theory but less to practice. Classroom lectures allow students to understand the organization limited to the rod, gear, cam or a combination of them. It is difficult for students have a better perceptual knowledge of the real life of theory of machines and mechanisms

(2) The chapters of this course are relatively independent and the basic is institutional analysis or institutional design, which is less contact with other courses. It is hard for students to systematically master the course.

(3) In the experimental or practical aspects, often, students in the same class may do the same subject. The subject may be too hard for some students or too easy for others. And some students may copy the one did a good job. In this way, it not only cannot reflect the individual differences in ability and interests of students, but also may restrict the ability of students to innovate.

The existence of the above problems makes the teaching of the theory of machines and mechanisms, which is originally strong in innovation, flexible in thinking and creation, may turn 
into inculcation to students. It usually leads to the theory disconnected, the dull teaching process and the blind learning objective. It would result in the decreased learning enthusiasm for students and the decline of the teaching quality for the teachers.

At present, many researchers introduce the cultivation of innovative ability and innovative design into the teaching of the theory of machines and mechanisms [4-8]. The research results show that this teaching method can cultivate the students' ability to think independently. And, students may ask questions, analyze problems and solve problems on the initiative. There are four aspects of the benefits as followings:

(1) Enhancing students' self-confidence.

(2) Promoting personal development.

(3) Improving scientific critical ability and the ability to explore and discover knowledge.

(4) Forming innovative spirit and solve practical problems

Shanghai Jian Qiao University mainly focuses on the application-oriented undergraduate education. Its purpose is to develop the higher education which is targeted at advanced application talents with production, management and service front-line. Students trained in college should be in a comprehensive and coordinated manner of training knowledge, ability and quality before graduation. The core of applied undergraduate education is "application". Therefore, the scientific orientation and the starting point of running a school for an applied undergraduate education are critical. The cultivation of "applied talents" is a process of gradual integration in theory and practice. The process should merge the mutual penetration of theoretical teaching and practical application [9]. Our major of mechanical design, manufacturing and automation professional is aimed at training applied engineering professionals. Thus, it puts forward the higher requirements for the teaching content, especially for the course of theory of machines and mechanisms. The college attaches a great importance to students' ability to innovate and practice, according to the professional orientation and characteristics of students. So, exploring an appropriate and feasible course teaching system closed to students' ability to innovate and engineering ability is very necessary.

\section{TEACHING REFORM}

\section{A. The combination of classroom heuristic teaching and extracurricular design work}

In the classroom teaching, the author introduces the innovation and application of the institution with examples. The author usually gives students some small design topics with novelty, interestingness and practicability. And the small design topics are always combined with the actual life to inspire students' learning. In this way, it could enable students to recognize the importance and popularity of this course. Meanwhile, it could also enable students to deepen their understanding and interest in the content of the course. For example, when the author explained the four-bar mechanism, she usually analyzed the working principle of the four-bar mechanism with examples of home sewing machines, umbrellas, bus doors, etc. In this way, it can further inspire students to look for the mechanisms that they have seen or used in their life. Thus, it can separate the basic components, sports vice from the mechanisms.

In addition, some mechanical competition events in recent years usually can be smartly introduced into class at the right time. For example, the "Shanghai Creation Cup Competitions", the "Shanghai Mechanical Innovation Competitions" and the "Shanghai Engineering Training Competitions" hosted by Shanghai Municipal Education Commission will be appropriately introduced in the classroom. The classical and award winning entries introduced to classes are coin sorting machine, carbon-free car, double degrees of freedom five-bar mechanism demonstrator, two-color printer, intelligent watering pot, automatic picking machine, weight climbing robot and so on. Students were encouraged to put forward the design proposal freely when they discuss in discussion classes. This way can guide students to actively think and stimulate the students' creativity. When students are allowed to design an organization by themselves, they can fully mobilize the enthusiasm for thinking. After they start their brains, they usually come up with different solutions. And then, they scrutinized, compared, and considered from the institutional feasibility, practicality, cost performance and other options. It will undoubtedly extend students' thinking and cultivate divergent thinking and innovative awareness through this exercise.

\section{B. Combination of theory and practice}

In order to cultivate students' awareness of engineering and make students more intuitive and understanding of the differences and connections between institutions, the group (four people one study group) will be assigned with the corresponding hands-on practical work two weeks before the relevant chapters. Before learning the basic knowledge of a planar four-bar mechanism, each team will make a hinge four-bar mechanism. The material, shape and size are not limited. However, to be as economical as possible. Students need to preview the relevant knowledge before completing their homework. Team members need to work together to find the ways to ensure the successful completion of the program. During class, when the author explained how to change the machine frame into different bodies, the condition of the crank, the emergency, the dead point, the driving angle, the pressure angle and the design of the four-bar mechanism, she usually used the mechanisms made by the students themselves. In this way, it could help students to build emotional awareness. The resulting impression coming from the mechanisms will be unforgettable. The student-made hinged four-bar mechanism is versatile. And students usually chosen the paper, refill, pen, chopstick, popsicle, ruler, wire, straw, plastic sheeting, clothes hanger, plastic bottle, broom, bamboo and wood, 3D printing and so on to make the four-bar mechanism. It could give a full play to their imagination and creativity. And everyone hold the fruits of their own work are confident and full of vitality. Although some students didn't exercise the four-bar mechanism, students will be more profound understanding of the four-bar mechanism, such as the conditions of the bar knowledge of the importance. However, this process can achieve four goals:

(1) Arousing the students' interest in learning and curiosity. 
(2) Activating the classroom atmosphere. The classroom atmosphere is active and will not be dead.

(3) Students are more willing to learn new knowledge than ever before.

(4) Taking the initiative to carry out self-learning to discover knowledge.

\section{Reforming curriculum design}

The theory of machines and mechanisms curriculum design is an important part of training the students' ability of mechanical movement design. In the curriculum design of this teaching session, the initiative is to give students to determine their own problems. The students used the learned knowledge to make the final product. Through this process, students can learn the initiative and innovative awareness to the limit. The choice of design topics is directly related to the quality of the design of the pros and cons. Taking into account the students uneven, there are three sources of curriculum design topics:

(1) The innovative design topics are developed by the students independently based on their own interest. These topics should be approved and reviewed by the instructor;

(2) The innovative design topics are arranged by the instructor (mostly from the previous mechanical design competition category);

(3) The traditional design topics are from the Mechanical design principles of course design guide.

The first two kinds of design topics are innovative topics, published to students before the course design and reported by the students, the latter one kind of design topics belongs to the traditional topic. Different types of topics will have the corresponding degree of difficulty. Students choose different subjects according to their own foundation, abilities and potentials. The curriculum design of "teaching students according to their aptitudes" can give full play to the potential of each student and embodies the modern teaching philosophy of taking education as the main body.

\section{Strengthening extra-curricular technological innovation training}

Schools always try to provide the hardware and software environments for college students to innovate. The author combined classes with extracurricular activities to create innovative ideas among college students. It could wake up the students from deep levels to inspire and tap the innovative potential of college students. We encourage students to translate some good ideas into contest works and competitions. The mechanical innovation contest is based on a complex and comprehensive mechanical product or mechanical system. An overall program design or even a physical prototype can be combined with basic knowledge of theoretical mechanics, material mechanics, mechanical design, machinery Principle, CNC machining, basic knowledge of machinery manufacturing, etc. We vigorously promote the organization of all kinds of competitions. In the 2017, our students separated ten teams attended the Shanghai Mechanical Innovation Contest. Nine of them awarded the prize and our college won the outstanding organizational units. By participating in the competition, students' innovative design abilities are enhanced and their enthusiasm for innovation can be stimulated. Students are encouraged to continuously improve and perfect their writing skills during their participation in the competition. At the same time, it can enhance the students' interest in learning and self-confidence.

\section{E. Combination of curriculum and research}

Under the circumstance of the rapid change of modern science and technology and the constant updating of professional knowledge, the students' awareness of information is enhanced and their ability to acquire and utilize information resources is enhanced. Students are encouraged to constantly absorb new knowledge, improve knowledge structure, self-learning ability and research ability. It is of great and profound significance to give full play to the creative ability. Students are encouraged to translate course design or award-winning works into patents during teaching. It requires students to make full use of the Internet, databases, related books and periodicals and a large number of relevant literatures. Through this training, students not only exercise the ability of researching and summarizing, but also enhance the students' lifelong learning ability, which helping them to timely update the knowledge structure in their future work and better conduct pioneering and creative work. From June 2016 to now, our students have applied for 14 utility model patents and 13 invention patents, of which utility model patents have been authorized.

\section{CONCLUSION}

Practice has proved that all the above methods have played a good effect on cultivating the students' innovative ability. Firstly, the use of the methods mentioned above arouses the students' interest in learning and curiosity. Meanwhile, the classroom atmosphere is active. Secondly, it undoubtedly promotes the cultivation and improvement of comprehensive quality such as student engineering practice ability and innovation ability. Thirdly, it enhances the students' self-confidence and extends students' cultivate divergent thinking and innovative awareness. Last, students are encouraged to constantly absorb new knowledge, improve the knowledge structure, self-learning ability and research ability.

\section{REFERENCES}

[1] Wei Yang, Xuefei Li, Ting Yang. Teaching Methods of Mechanical Principles and Cultivation of Students' Creative Ability [J]. China Modern Educational Equipment, 2009,(17):121-123.

[2] Li Du. Reform of "Mechanical Principle" Curriculum and Cultivation of College Students' Creative Ability [J]. Journal of Chengdu Normal University, 2002, 05:69-70+72.

[3] Liangbo Sun, Jianyi Kong, Meifa Huang, Hui Gui. Research on and practice of the machine innovate design project in mechanisms and machine theory teaching [J]. Machinery, 2010, 12:21-23+33.

[4] Xi Benqiang, Wang Qi, Qu Hui, Research and practice in creative teaching mode of course design on theory of machines and mechanisms[J]. China Modern Educational Equipment,, 2010,21:94-95+98.

[5] Qingyun Liu, Ruiming Qian. Mechanical Principle Courses Teaching Based on Innovative Ability [J]. Education Teaching Forum, 2012,16:33-34

[6] Hui Wang. The Exploration of Mechanical Principle Course Construction Based on the Cultivation of Innovation Ability [J]. Hebei Vocational Education, 2012,04:108-109.

[7] Jian Hua, Qingshi Huang, Chuanxi Zhou. Exploration of Cultivating Students' Innovative Ability in Course of "Principle of Machinery"[J]. Higher Education Forum, 2007,06:80-81+65. 
[8] Lixia Hou, Juncai Hou, Hongli Guo, Junchang Zhang. Introducing Innovative Design into Teaching of Principles of Machinery [J]. China Educational Technology \& Equipment,2014,24:139-140.

[9] Dasheng Li, Huairong Shi, Ming Lv Chunyan Zhang. Teaching Reform and Practice for Mechanical Theory in Applied Undergraduate Colleges[J]. Journal of Huaihai Institute of Technology(Humanities \& Social Sciences Edition), 2012, 10(3):90-92. 